\title{
Comparative study of Levofloxacin and its amide derivative as efficient water soluble inhibitors for mild steel corrosion in hydrochloric acid solution
}

\author{
Turuvekere K. Chaitra ${ }^{1} \cdot$ Kikkeri N. Mohana $^{1} \cdot$ Harmesh C. Tandon ${ }^{2}$
}

Received: 17 December 2015/Accepted: 24 April 2016/Published online: 9 May 2016

(c) The Author(s) 2016. This article is published with open access at Springerlink.com

\begin{abstract}
The influence of 8-fluoro-3-methyl-9-(4-methylpiperazin-1-yl)-6-oxo-2,3-dihydro-6H-1-oxa-3a-aza-phenalene-5-carboxylic acid or levofloxacin (P1) and newly synthesized 8-fluoro-3-methyl-9-(4-methyl-piperazin-1yl)-6-oxo-2,3-dihydro-6H-1-oxa-3a-aza-phenalene-5-carboxylic acid-(5-methyl-pyridin-2-yl)-amide (P2) on corrosion inhibition of mild steel in $0.5 \mathrm{M}$ hydrochloric acid solution was studied using weight loss and electrochemical techniques. Inhibition efficiency of P1 and P2 increased with concentration and decreased with temperature in the concentration range $0.14-0.35 \mathrm{mM}$ in the temperature range 303-333 K. Thermodynamic parameters for dissolution and adsorption process were studied. Increase in energy of activation after the addition of inhibitors indicated formation of barrier film which prevents charge and mass transfer. Free energy of adsorption showed that the type of adsorption was neither physical nor chemical but comprehensive. The adsorption of the P1 and P2 on the mild steel surface was found to obey the Langmuir isotherm. Impedance measurement showed that there is increase in the polarization resistance and decrease in double layer capacitance after the addition of inhibitors. From polarization study as the shift in corrosion potential is more than $85 \mathrm{mV}$, both $\mathrm{P} 1$ and $\mathrm{P} 2$ are anodic type of inhibitors. Scanning electron microscope images confirm the formation of inhibitory film on mild steel surface. Quantum chemical calculation results well correlated with
\end{abstract}

Kikkeri N. Mohana

drknmohana@gmail.com

1 Department of Studies in Chemistry, Manasagangotri, University of Mysore, Mysuru 570006, Karnataka, India

2 Department of Chemistry, Sri Venkateswara College, Dhaula kuan, New Delhi 110021, India experimental results. Lower values of energy gap, ionization potential and hardness, higher value of softness make P2 better inhibitor compared to P1.

Keywords Corrosion · Mild steel · Levofloxacin · Electrochemical techniques - Quantum chemical parameters $\cdot$ SEM

\section{Introduction}

Corrosion is a natural destructive phenomenon where pure metals interact with the environment to form non-desirable metallic compounds. Protection of metals from corrosion is one of the major economic issues. Mild steel (MS) is an important metal which is widely applied in oil wells, constructional materials, automobiles and many other industries due to its excellent mechanical properties and low cost [1]. Hydrochloric acid solutions (approximately $0.5-1 \mathrm{M})$ are widely used in several industrial processes, some of the important fields of application being acid pickling of steel, chemical cleaning and processing, ore production and oil well acidification [2]. Corrosion of MS when exposed to aggressive acids, such as hydrochloric acid and sulfuric acid results in such damage that needs either repair or replacement of the part leading to huge loss of resources. Corrosion of MS is worth investigating because such corrosions cause damage to pipelines, bridges, marine structures and construction materials bringing heavy economic losses worldwide. Corrosion is also one of the major concerns in the durability of materials and structures; and studies are continuously carried out to develop effective methods for corrosion control [3]. There are a number of methods for corrosion control but the choice depends on economics, safety requirements and 
technical considerations. Mitigation of MS corrosion is achieved through such means as galvanisation, organic coating (enamel, polymer, oils etc.) and using corrosion inhibitors [4-6] which form film by adsorbing on the metal surface. The organic corrosion inhibitors although proved to be the best for the protection of MS, but they are restricted in some cases because of their toxicity. Therefore, the best means of protection is to adapt an inhibitor which is eco-friendly, easily soluble and effective at low concentration. The class of organic compounds which satisfy these conditions are drugs and their derivatives which are highly water soluble.

Corrosion inhibition studies of many drugs, such as $\beta$ lactam antibiotics \{penicillin G [7], ampicillin [8], amoxicillin [9]\}, quinolones \{ofloxacin [10], ciprofloxacin [11], quinoline [12]\}, tetracyclines $\{$ doxycycline [13]\}, sulphonamides \{sulfamethazine [14], dapsone [15] antifungal \{ketoconazole [16]\}, antiviral \{rhodanine [17]\}, have been reported.

Levofloxacin is a member of the fluoroquinolone class of antibacterial used in the treatment of chronic bronchitis, respiratory tract infection, pneumonia, skin infection and urinary tract infection [18]. Its structure has extended $\pi$ electron systems, good number of hetero atoms and two electron donating methyl groups which facilitate its adsorption on the MS surface. Fluoroquilones have been established as potential class of inhibitors, P1 and P2 which belong to the same class are expected to give good inhibition because similar molecules tend to behave alike [19]. Eddy et al. [20] studied derivatives of fluoroquinolone (ofloxacin, amifloxacin, enofloxacin, pefloxacin) on MS corrosion in sulfuric acid medium by gravimetric technique supported by quantum chemical calculations and obtained inhibition efficiency up to $94 \%$. Levofloxacin was previously studied by Pang et al. [21] as MS corrosion inhibitor in sulfuric acid medium by weight loss and electrochemical methods and maximum inhibition efficiency obtained was $90 \%$. In this study, Levofloxacin is being studied as MS corrosion inhibitor in $\mathrm{HCl}$ medium using gravimetric and electrochemical techniques at lower concentrations and the results are supported by theoretical studies. Comparison of inhibition efficiency of Levofloxacin with its synthesized derivative has been made to study the effect of an extra heterocyclic ring and an amine group transformed into amide bond present in $\mathrm{P} 2$.

In continuation of our previous work [22-26] the present paper reports the comparative study of the anticorrosion potential of levofloxacin (P1) and its newly synthesized amide derivative (P2) in $0.5 \mathrm{M} \mathrm{HCl}$ media using weight loss method, electrochemical impedance spectrosocpy (EIS) and potentiodynamic polarization measurements. Morphological study has been done using scanning electron microscope (SEM). Quantum chemical calculations were done and different parameters, such as energies of highest occupied molecular orbital $\left(E_{\mathrm{HOMO}}\right)$ and the lowest unoccupied molecular orbital $\left(E_{\mathrm{LUMO}}\right)$, the energy gap $(\Delta E)$, hardness $(\eta)$, softness $(\sigma)$, electron affinity $(A)$, electronegativity $(\chi)$, ionization potential (I) of P1 and P2 were determined and correlated with experimental results.

\section{Experimental}

\section{Materials and sample preparation}

The chemical composition by wt $\%$ of MS coupons used for experiment was as follows: C, 0.051; Mn, 0.179; Si, 0.006; P, 0.005; S, 0.023; Cr, 0.051; Ni, 0.05; Mo, 0.013; Ti, 0.004; Al, 0.103; Cu, 0.050; Sn, 0.004; B, 0.00105; Co, 0.017 ; $\mathrm{Nb}, 0.012 ; \mathrm{Pb}, 0.001$ and the remaining is iron. Before the commencement of experiment, samples were mechanically cut into $2 \mathrm{~cm} \times 2 \mathrm{~cm} \times 0.1 \mathrm{~cm}$, abraded with different grades of silicon carbide emery paper, washed with double distilled water, degreased, dried and stored in desiccator until use. For polarization and impedance measurements, the MS specimens were embedded in epoxy resin to expose a geometrical surface area of $1 \mathrm{~cm}^{2}$ to the electrolyte. Solutions of P1 and P2 in optimized concentration range of $0.14-0.35 \mathrm{mM}$ were prepared from stock solution made of using $0.5 \mathrm{M} \mathrm{HCl}$. Melting range was determined using Veego Melting Point VMP III apparatus.

\section{Synthesis of 8-fluoro-3-methyl-9-(4-methyl- piperazin-1-yl)-6-oxo-2,3-dihydro-6H-1-oxa-3a-aza- phenalene-5-carboxylic acid-(5-methyl-pyridin-2- yl)-amide (P2)}

The reported procedure [26] of acid-amine coupling was used for the synthesis of P2. Scheme for the synthesis of P2 is given in Fig. 1. To a mixture of 8-fluoro-3-methyl-9-(4methyl-piperazin-1-yl)-6-oxo-2,3-dihydro-6H-1-oxa-3aaza-phenalene-5-carboxylic acid (1 equivalent) and 5-methyl-pyridin-2-ylamine (1 equivalent), triethylamine (2.1equivalent) and O-(Benzotriazol-1-yl)- $N, N, N^{\prime}, N^{\prime}$-tetramethyluronium tetrafluoroborate (TBTU) (1.2 equivalent) were added in dichloromethane (MDC). The reaction mixture was stirred at room temperature for $16 \mathrm{~h}$. Reaction completion was monitored by TLC using solvent system, ethyl acetate: methanol (1:1). Reaction mixture was washed with $1 \mathrm{M} \mathrm{HCl}, 10 \%$ bicarbonate solution followed by water and brine, dried over sodium sulfate, and concentrated to remove solvent under reduced pressure. The solid obtained was crystallized using ethanol to get the pure form. The yield of the product was $90 \%$ and melting range 

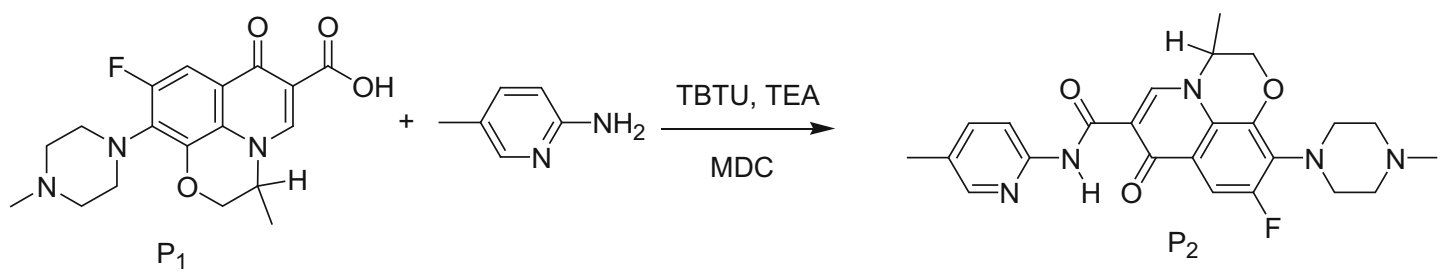

Fig. 1 Scheme for the synthesis of inhibitors

was 606-607 K. Spectral data: IR $\left(\mathrm{cm}^{-1}\right) 1673(\mathrm{C}=\mathrm{O}$, Amide), 3398 (N-H, Amide), 1673 (C=O, ketone), 1003-1095 (C-F), $\quad 1450-1599 \quad(\mathrm{Ar} \quad \mathrm{C}=\mathrm{C}),{ }^{1} \mathrm{H}-\mathrm{NMR}$ $\left(400 \mathrm{MHz}, \mathrm{DMSO}-\mathrm{d}_{6}\right) \delta_{\mathrm{H}} \mathrm{ppm}: 1.56\left(\mathrm{~s}, 3 \mathrm{H}, \mathrm{CH}_{3}\right), 1.57(\mathrm{~s}$, $\left.3 \mathrm{H}, \mathrm{CH}_{3}\right), 2.04-2.16(\mathrm{~m}, 4 \mathrm{H}$, piperazine), 2.17-2.35 (m, $4 \mathrm{H}$, piperazine), $2.54\left(\mathrm{~s}, 3 \mathrm{H}, \mathrm{N}-\mathrm{CH}_{3}\right), 4.42-4.38(\mathrm{~m}, 3 \mathrm{H}$, $\mathrm{CH}_{2} \mathrm{CH}$ ), 7.25-7.26 (d, $1 \mathrm{H}$, phenyl), 7.48-7.51 (d, $1 \mathrm{H}$, phenyl), 7.69 (s, 1H, phenyl), 8.188 (s, 1H, phenyl), 8.61 (s, 1H, phenyl), $12.55(\mathrm{~s}, 1 \mathrm{H}, \mathrm{N}-\mathrm{H})$. MS: $452.12(\mathrm{M}+1)$, $453.12(\mathrm{M}+2)$.

\section{Weight loss measurements}

MS specimens were immersed in $0.5 \mathrm{M} \mathrm{HCl}$ solution without and with varying amounts of inhibitor for $4 \mathrm{~h}$ in a thermostatically controlled water bath (with an accuracy of $\pm 0.2 \mathrm{~K}$ ) at constant temperature, under aerated condition (Weiber limited, Chennai, India). The coupons were taken out after $4 \mathrm{~h}$ of immersion, rinsed in water followed by drying in acetone. Weight loss of the specimens was recorded by analytical balance (Sartorius, precision $\pm 0.1 \mathrm{mg}$ ). Experiment was carried out in triplicates and mean weight loss was calculated. The procedure was repeated for all other concentrations and temperatures.

\section{Electrochemical measurements}

Potentiodynamic polarization and EIS experiments were carried out using a CHI660D electrochemical workstation. A conventional three-electrode cell consisting of $\mid \mathrm{Ag} / \mathrm{AgCl}$ reference electrode, a platinum auxiliary electrode and the working MS electrode with $1 \mathrm{~cm}^{2}$ exposed areas was used. Pre-treatment of the specimens was same as gravimetric measurements. The electrochemical tests were performed with $\mathrm{P} 1$ and P2 concentrations ranging from 0.14 to $0.35 \mathrm{mM}$ at $303 \mathrm{~K}$. Potentiodynamic polarization measurements were performed in the potential range from -850 to $-150 \mathrm{mV}$ with a scan rate of $0.4 \mathrm{mV} \mathrm{s}^{-1}$. The exposure time before polarization measurements was $30 \mathrm{~min}$. Prior to EIS measurement; 30 min were spent for making open circuit potential a stable value. The EIS data were taken in the frequency range of $10 \mathrm{kHz}-1 \mathrm{~Hz}$.

\section{Quantum chemical calculations}

The geometrical optimization of the investigated molecules was done by $\mathrm{Ab}$ initio method at $6-31 \mathrm{G}^{* *}$ basis set for all atoms. For energy minimization, the convergence limit at 1.0 and rms gradient $1.0 \mathrm{kcal} / \mathrm{Amol}$ was kept. The PolakRibiere conjugate gradient algorithm which is quite fast and precise was used for optimization of geometry. In DFR calculation B3LYP combined exchange-corelation potential functional has been used. The HYPERCHEM 7.52 (Hypercube Inc., Florida, USA, 2003) professional software was employed for all calculations.

\section{Scanning electron microscopy (SEM)}

The SEM experiments were performed using a Zeiss electron microscope with the working voltage of $15 \mathrm{kV}$ and the working distance $10.5 \mathrm{~mm}$. In SEM micrographs, the specimens were exposed to $0.5 \mathrm{M} \mathrm{HCl}$ in the absence and presence of inhibitors under optimum conditions after $4 \mathrm{~h}$ of immersion. The SEM images were taken for polished MS specimen and specimen immersed in acid solution with and without inhibitors.

\section{Results and discussion}

\section{Weight loss measurement}

\section{Effect of inhibitor concentration}

The effect of concentration of inhibitors P1 and P2 on MS corrosion in $0.5 \mathrm{M} \mathrm{HCl}$ was studied at concentrations from 0.14 to $0.35 \mathrm{mM}$ and temperature range of 303 to $333 \mathrm{~K}$ by weight loss measurement and results are presented in Table 1 . The corrosion rate and inhibition efficiency were calculated using the formulae (1) and (2).

$C_{\mathrm{R}}=\frac{\Delta W}{S t}$

$\operatorname{IE}(\%)=\frac{\left(C_{\mathrm{R}}\right)_{\mathrm{a}}-\left(C_{\mathrm{R}}\right)_{\mathrm{p}}}{\left(C_{\mathrm{R}}\right)_{\mathrm{a}}} \times 100$

where, $\Delta W$ is the weight loss, $S$ is the surface area of the specimen $\left(\mathrm{cm}^{2}\right), t$ is the immersion time $(h)$, and $\left(C_{R}\right)_{a}$, 
Table 1 Weight loss data in the absence and presence of inhibitors in $0.5 \mathrm{M} \mathrm{HCl}$ at different concentrations and temperatures

\begin{tabular}{|c|c|c|c|c|c|c|c|c|c|}
\hline Inhibitor & $C(\mathrm{mM})$ & & IE $(\%)$ & & IE $(\%)$ & & IE $(\%)$ & & IE (\%) \\
\hline Blank & - & 0.516 & - & 0.883 & - & 1.224 & - & 1.65 & - \\
\hline \multirow[t]{4}{*}{ P1 } & 0.14 & 0.087 & $83.0 \pm 0.79$ & 0.165 & $81.3 \pm 0.44$ & 0.244 & $80.1 \pm 0.43$ & 0.366 & $77.8 \pm 0.41$ \\
\hline & 0.21 & 0.068 & $86.7 \pm 0.58$ & 0.136 & $84.5 \pm 0.35$ & 0.205 & $83.3 \pm 0.32$ & 0.338 & $79.5 \pm 0.52$ \\
\hline & 0.28 & 0.047 & $90.8 \pm 0.49$ & 0.118 & $86.6 \pm 0.50$ & 0.183 & $85.0 \pm 0.54$ & 0.306 & $81.4 \pm 0.86$ \\
\hline & 0.35 & 0.030 & $94.0 \pm 0.68$ & 0.097 & $89.0 \pm 0.32$ & 0.161 & $86.8 \pm 0.55$ & 0.297 & $82.0 \pm 0.76$ \\
\hline \multirow[t]{4}{*}{$\mathrm{P} 2$} & 0.14 & 0.072 & $86.0 \pm 0.22$ & 0.133 & $84.9 \pm 0.65$ & 0.220 & $82.0 \pm 0.45$ & 0.345 & $79.0 \pm 0.82$ \\
\hline & 0.21 & 0.056 & $89.1 \pm 0.52$ & 0.115 & $87.0 \pm 0.88$ & 0.195 & $84.0 \pm 0.38$ & 0.313 & $81.0 \pm 0.97$ \\
\hline & 0.28 & 0.035 & $93.2 \pm 0.92$ & 0.097 & $89.0 \pm 0.84$ & 0.173 & $85.8 \pm 0.64$ & 0.302 & $81.7 \pm 1.06$ \\
\hline & 0.35 & 0.018 & $96.4 \pm 0.88$ & 0.078 & $91.1 \pm 0.75$ & 0.155 & $87.3 \pm 0.88$ & 0.287 & $82.6 \pm 0.72$ \\
\hline
\end{tabular}

$\left(C_{R}\right)_{p}$ are corrosion rates in the absence and presence of the inhibitor, respectively.

As the concentration increases, IE (\%) increases for both $\mathrm{P} 1$ and $\mathrm{P} 2$. As the concentration increases, availability of number of molecules to block reaction sites increases. The highest inhibition efficiency of 96 and $94 \%$ were shown by $\mathrm{P} 2$ and $\mathrm{P} 1$ at $0.35 \mathrm{mM}$ concentration, respectively. After that although concentration was raised and there was no much difference in inhibition efficiency.

\section{Effect of temperature}

Inhibition performance of $\mathrm{P} 1$ and $\mathrm{P} 2$ on $\mathrm{MS}$ in $0.5 \mathrm{M} \mathrm{HCl}$ was studied in the temperature range of $303-333 \mathrm{~K}$ (Table 1). The influence of temperature on corrosion reaction is very complex, because many changes take place on the metal surface, such as etching, desorption and inhibitor itself may undergo decomposition [27]. The corrosion rate of MS increases as the temperature of the surrounding solution increases both in the absence and presence of inhibitors. That is IE (\%) decreases as the temperature increases. This is due to decrease in hydrogen evolution over potential which in turn increases the evolution of anodic hydrogen at higher temperatures. There is also possibility of desorption of adsorbed inhibitor film, as the inhibitor molecules gain sufficient energy to overcome interaction between metal empty orbital and inhibitor electrons at higher temperature.

The relationship between corrosion rate of MS and temperature of the environment is given by Arrhenius equation

$C_{\mathrm{R}}=k \exp \left(-\frac{E_{\mathrm{a}}^{*}}{R T}\right)$

Enthalpy and entropy of the activation are calculated based on transition state theory using the alternative form of Arrhenius equation, which takes the form as
$C_{\mathrm{R}}=\frac{R T}{N h} \exp \left(\frac{\Delta S_{\mathrm{a}}^{*}}{R}\right) \exp \left(\frac{-\Delta H_{\mathrm{a}}^{*}}{R T}\right)$

where, $E_{\mathrm{a}}^{*}$ is activation energy, $\Delta S_{\mathrm{a}}^{*}$ is the entropy of activation, $\Delta H_{\mathrm{a}}^{*}$ is the enthalpy of activation, $k$ is Arrhenius pre-exponential factor, $h$ is Planck's constant, $N$ is Avogadro's number, $T$ is the absolute temperature and $R$ is the universal gas constant.

The plot of $\ln C_{\mathrm{R}}$ versus $1 / T$ is a straight line (Fig. 2), computing the values of slope and intercept, the values of $E_{a}^{*}$ and $k$ were calculated for both the inhibitors at various concentrations. Using the Eq. (4), another linear plot of $\mathrm{ln}$ $C_{\mathrm{R}} / T$ versus $1 / T$ was drawn (Fig. 3$)$ with slope $\left(-\Delta H_{a}^{*} / R\right)$ and intercept $\left[\ln (R / N h)+\Delta S_{\mathrm{a}}^{*} / R\right]$. This was used for the calculation of $\Delta H_{\mathrm{a}}^{*}$ and $\Delta S_{\mathrm{a}}^{*}$. Different parameters involving Arrhenius equations were calculated and listed in Table 2.

Review of these data indicates that all the activation parameters of dissolution reaction of $\mathrm{MS}$ in $0.5 \mathrm{M} \mathrm{HCl}$ are higher in the presence of inhibitors than in their absence. $E_{\mathrm{a}}^{*}$ is higher for inhibited solution than for uninhibited solution and increases upon increasing concentration of inhibitors. Such a trend suggests that corrosion reaction will be further pushed to surface sites which are characterized by progressively higher value of $E_{\mathrm{a}}^{*}$ as concentration of the inhibitor becomes higher [28]. At higher concentration $E_{\mathrm{a}}^{*}$ increases further, because extent of surface coverage is close to saturation [29]. The higher values of $E_{\mathrm{a}}^{*}$ in inhibited solution might also be correlated with the increased thickness of double layer [30]. Further from the value of $E_{\mathrm{a}}^{*}$ which is greater than $20 \mathrm{~kJ} \mathrm{~mol}^{-1}$ for both inhibited and uninhibited solutions, it is confirmed that the whole process is surface controlled [31]. The positive sign of enthalpies shows endothermic nature of MS dissolution process i.e., dissolution of steel is difficult [32]. After the addition of $\mathrm{P} 1$ and $\mathrm{P} 2$ there is increase in the value of enthalpy of activation which suggests that the dissolution becomes more difficult. Entropy of activation is negative in the presence and absence of P1 and P2 which becomes 

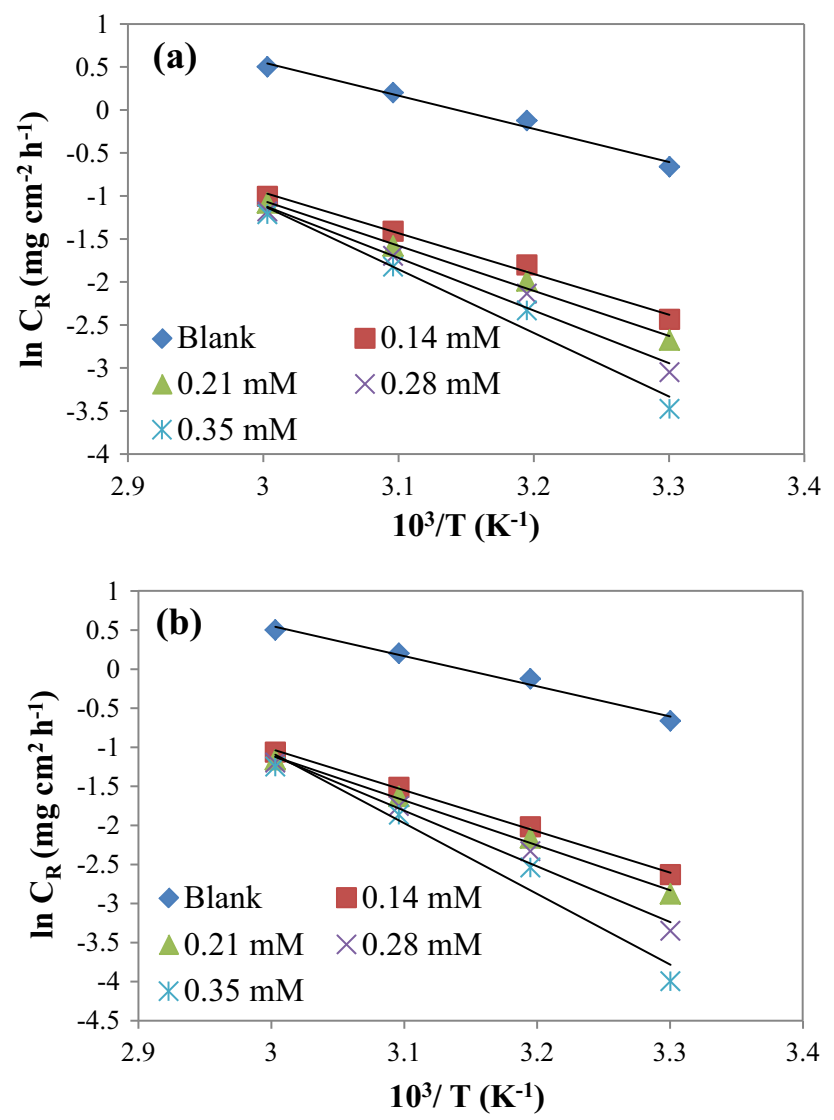

Fig. 2 Arrhenius plots in the absence and presence of different concentrations of a P1 and b P2

more positive on increasing concentration of inhibitor. This indicates that the dissolution of MS is characterized by an activated complex which is associative. This might be due to the adsorption of P1 and P2 molecules from $\mathrm{HCl}$ solution which could be regarded as quasi- substitution between the inhibitors in the aqueous phase and water molecules on MS electrode surface. In such a situation, the adsorption of P1 and P2 on MS surface which results in decrease in entropy was accompanied with desorption of water molecules from the electrode surface which increases the entropy. Here entropy is the sum of solvent entropy and solute entropy. Thus, increase in entropy of activation for $\mathrm{P} 1$ and $\mathrm{P} 2$ was attributed to predominance of solvent $\left(\mathrm{H}_{2} \mathrm{O}\right)$ entropy [33].

\section{Adsorption isotherm}

The efficiency of a compound as successful corrosion inhibitor mainly depends on its adsorption ability on the metal surface. It is essential to know the mode of adsorption and the adsorption isotherm that can give valuable information on the interaction of inhibitor and metal surface [34]. The adsorption of an organic adsorbate at a
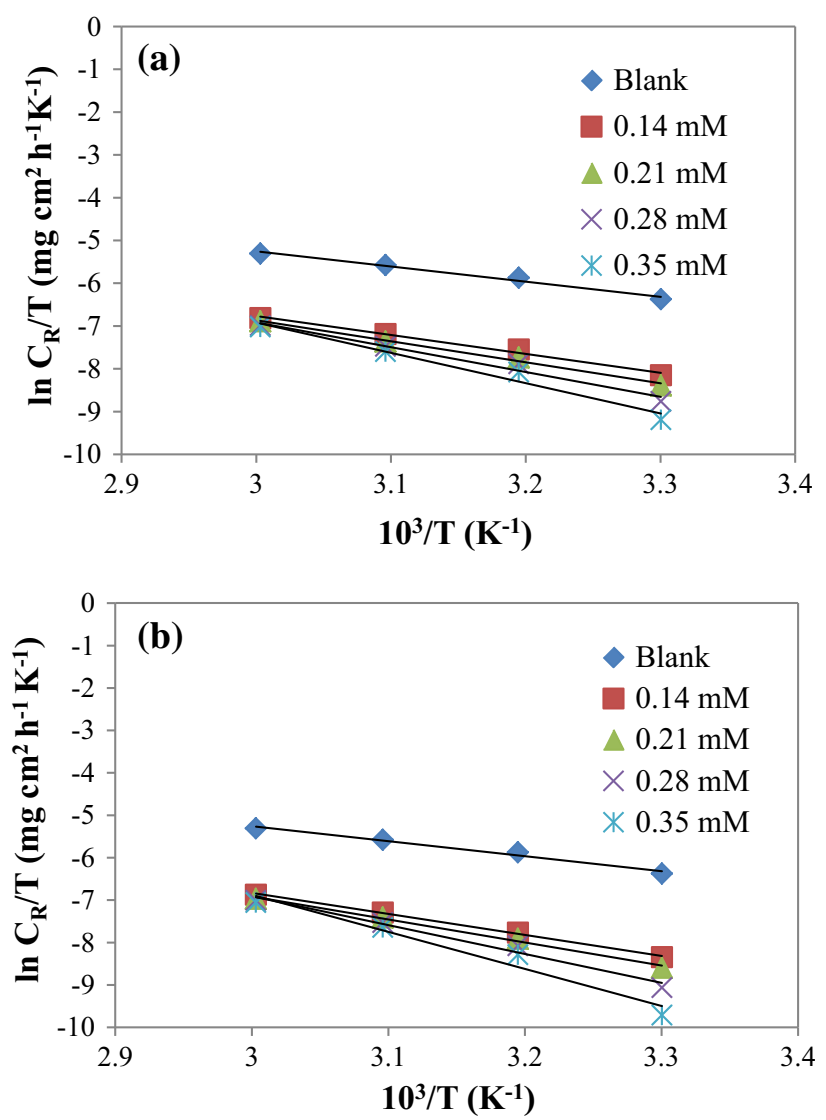

Fig. 3 Alternative Arrhenius plots in the absence and presence of different concentrations of $\mathbf{a} \mathrm{P} 1$ and $\mathbf{b} \mathrm{P} 2$

metal/solution interface can be presented as a substitution adsorption process between the organic molecules in aqueous solution and the water molecules on a metallic surface. All isotherms are having general formula

$f(\theta, x) \exp (-2 \alpha \theta)=K_{\text {ads }} C$

where, $f(\theta, x)$ is the configurational factor which depends upon the physical mode of adsorption. Here $\theta$ is the surface coverage, $C$ is the concentration of the inhibitor, $x$ is the size factor ratio, $\alpha$ is the molecular interaction parameter and $K_{\text {ads }}$ is the equilibrium constant of the adsorption process [35]. Depending on the value of correlation coefficient the best fitter of the isotherm can be determined. After trying to fit the values to many isotherms like Temkin, Frumkin, Freundlich and Langmuir, the best fit was obtained with Langmuir adsorption isotherm for the inhibitors. A plot of $C / \theta$ versus $C$ (Fig. 4) gave a straight line with an average correlation coefficient of 0.9995 and 0.9995 , for P1 and P2, respectively and a slope of nearly unity (1.0706 and 0.9995 for P1 and P2, respectively) suggests that the adsorption of both the molecules obeys Langmuir isotherm, which can be expressed by the following equation: 
Table 2 Activation parameters in the absence and presence of $\mathrm{P} 1$ and $\mathrm{P} 2$ in $0.5 \mathrm{M} \mathrm{HCl}$

\begin{tabular}{lllllll}
\hline Inhibitor & $C(\mathrm{mM})$ & $E_{\mathrm{a}}^{*}\left(\mathrm{~kJ} \mathrm{~mol}^{-1}\right)$ & $k\left(\mathrm{mg} \mathrm{cm}^{-2} \mathrm{~h}^{-1}\right)$ & $\begin{array}{l}\Delta H_{\mathrm{a}}^{*} \\
\left(\mathrm{~kJ} \mathrm{~mol}{ }^{-1}\right)\end{array}$ & $\Delta H_{\mathrm{a}}^{*}=E_{\mathrm{a}}{ }^{*}-\mathrm{RT}\left(\mathrm{kJ} \mathrm{mol}^{-1}\right)$ & $\Delta S_{\mathrm{a}}^{*}\left(\mathrm{~J} \mathrm{~mol}^{-1} \mathrm{~K}^{-1}\right)$ \\
\hline Blank & - & 32.1 & 186,465 & 29.5 & 29.5 & -152.9 \\
P1 & 0.14 & 39.3 & 564,671 & 36.7 & 36.8 & -143.6 \\
& 0.21 & 43.5 & $2,317,501$ & 40.9 & 40.9 & -131.9 \\
& 0.28 & 50.9 & $31,077,666$ & 48.2 & 48.3 & -110.3 \\
& 0.35 & 61.5 & $1.41 \times 10^{9}$ & 58.8 & 58.9 & -78.6 \\
P2 & 0.14 & 43.8 & $2,610,363$ & 41.1 & 41.2 & -130.9 \\
& 0.21 & 47.8 & $10,201,038$ & 45.1 & 45.2 & -85.2 \\
& 0.28 & 59.2 & $6.35 \times 10^{8}$ & 56.6 & 56.6 & -37.0 \\
\hline
\end{tabular}
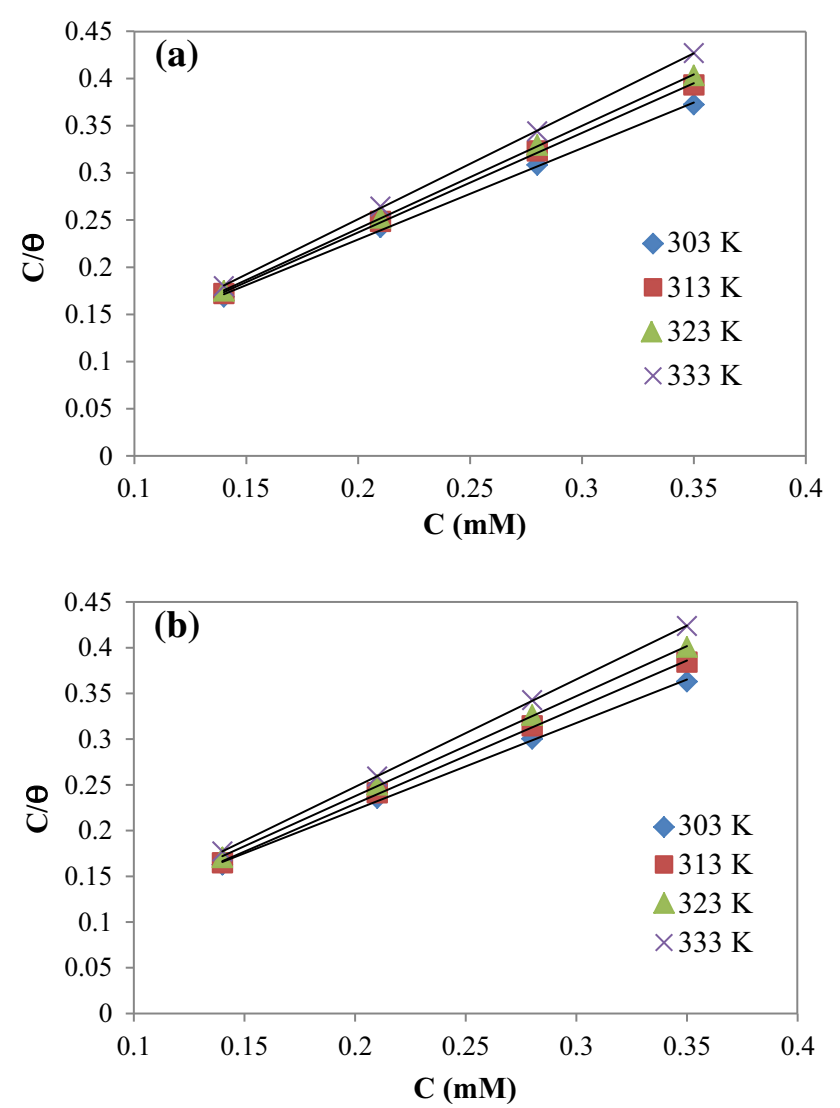

Fig. 4 Langmuir isotherm for the adsorption of a P1 and b P2 in $0.5 \mathrm{M} \mathrm{HCl}$ at different temperatures

$C / \theta=\frac{1}{K_{\mathrm{ads}}}+C$

From Eq. (6), $K_{\text {ads }}$ can be calculated from intercept of $C / \theta$ Vs $C$ plot. Free energy of adsorption can be calculated from $K_{\text {ads }}$ using the Eq. (7).

$\Delta G_{\text {ads }}^{o}=-R T \ln \left(55.5 K_{\text {ads }}\right)$ where, $R$ is gas constant and $T$ is the absolute temperature of the experiment and the constant value 55.5 is the concentration of water in solution in $\mathrm{mol} \mathrm{dm}^{-3}$.

Entropy of adsorption and enthalpy of adsorption process can be calculated using the following thermodynamic equation:

$\Delta G_{\mathrm{ads}}^{o}=\Delta H_{\mathrm{ads}}^{o}-T \Delta S_{\mathrm{ads}}^{o}$

The values of all thermodynamic parameters are listed in Table 3. A plot of $\Delta G_{\text {ads }}^{o}$ versus $T$ gives a straight line (Fig. 5) which can be used for the calculation of $\Delta H_{\text {ads }}^{o}$ and $\Delta S_{\text {ads. }}^{o}$. Calculated values of free energy of adsorption and adsorption equilibrium constant together represent spontaneity of the process and stability of the adsorbed layer on the metal surface. Large values of $K_{\text {ads }}$ obtained for P1 and P2 indicate that they are efficient adsorbents which imply that they have better inhibition efficiency. In general, the values of $\Delta G_{\text {ads }}^{o}$ up to $-20 \mathrm{~kJ} \mathrm{~mol}^{-1}$ are compatible with the electrostatic interaction between the charged inhibitor molecules and the charged metal surface (physisorption), and those which are more negative than $-40 \mathrm{~kJ} \mathrm{~mol}^{-1}$ involve charge sharing or charge transfer from the inhibitor molecules to the metal surface (chemisorption) [36]. The calculated values of free energy of adsorption for P1 and P2 lies between -20 and $-40 \mathrm{~kJ} \mathrm{~mol}^{-1}$ at lower temperatures and little higher than $-40 \mathrm{~kJ} \mathrm{~mol}^{-1}$ at higher temperatures. Many authors reported that the adsorption of organic molecules on the solid surfaces cannot be considered as purely physical or as purely chemical [37-39]. Initially inhibitor may adsorb on the MS surface by electrostatic force of attraction but at later stage charge transfer also takes place. Therefore, it is concluded that the adsorption of P1 and P2 is neither totally physical nor chemical but complex comprehensive kind of adsorption involving both with a slight dominance of chemisorption. Similar type of observations have been reported in the literature [40-43]. 
Table 3 Adsorption thermodynamic parameters in the absence and presence of various concentrations of inhibitors

\begin{tabular}{|c|c|c|c|c|c|c|c|}
\hline Inhibitor & $\mathrm{T}(\mathrm{K})$ & $R^{2}$ & $K_{\text {ads }}\left(\mathrm{L} \mathrm{mol}^{-1}\right)$ & $\begin{array}{l}\Delta G_{\text {ads }}^{\mathrm{o}} \\
\left(\mathrm{kJ} \mathrm{mol}^{-1}\right)\end{array}$ & $\Delta S_{\text {ads }}^{\mathrm{o}}\left(\mathrm{J} \mathrm{mol}{ }^{-1} \mathrm{~K}^{-1}\right)$ & $\begin{array}{l}\Delta H_{\text {ads }}^{\mathrm{o}} \\
\left(\mathrm{kJ} \mathrm{mol}^{-1}\right)\end{array}$ & $\begin{array}{l}\Delta G_{\text {ads }}^{\mathrm{o}}=\Delta H^{\mathrm{o}}{ }_{\text {ads }}-T \Delta S_{\text {ads }}^{\mathrm{o}} \\
\left(\mathrm{kJ} \mathrm{mol}^{-1}\right)\end{array}$ \\
\hline \multirow[t]{4}{*}{ P1 } & 303 & 0.9989 & 27,855 & -36.2 & -209 & 27.7 & -35.8 \\
\hline & 313 & 0.9996 & 38,461 & -38.6 & & & -37.8 \\
\hline & 323 & 0.9999 & 43,290 & -40.0 & & & -40.0 \\
\hline & 333 & 0.9999 & 60,606 & -41.6 & & & -42.1 \\
\hline \multirow[t]{4}{*}{$\mathrm{P} 2$} & 303 & 0.9987 & 30,769 & -35.9 & -201 & 24.7 & -36.3 \\
\hline & 313 & 0.9995 & 49,504 & -37.9 & & & -38.3 \\
\hline & 323 & 0.9998 & 53,475 & -39.5 & & & -40.3 \\
\hline & 333 & 1.0000 & 80,000 & -42.4 & & & -42.3 \\
\hline
\end{tabular}

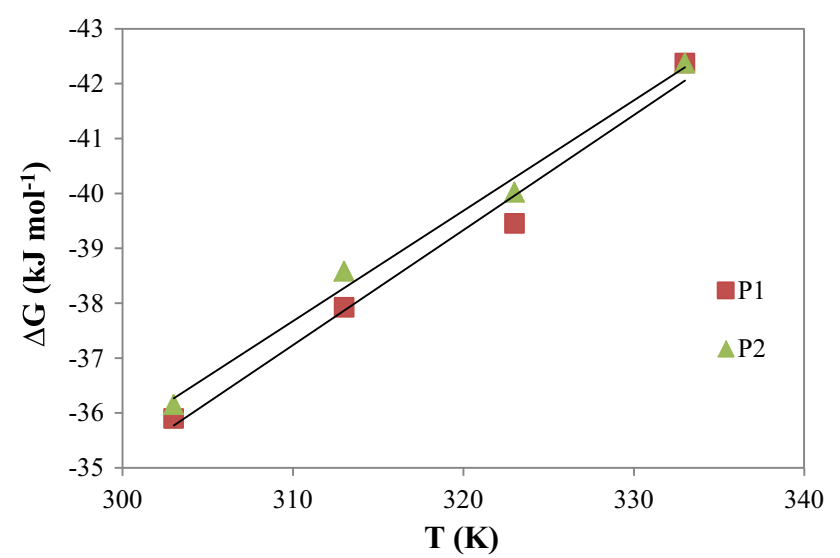

Fig. 5 Plot of $\Delta G_{\text {ads }}$ vs $T$ for P1 and P2

\section{Electrochemical impedance spectroscopy}

The corrosion behavior of P1 and P2 was studied using EIS and results are tabulated in Table 4. Nyquist plot, bode modulus plot and phase angle plot of $\mathrm{P} 1$ and $\mathrm{P} 2$ are given in Figs. 6 and 7, respectively. Nyquist plots for all concentrations are characterized by one capacitive loop whose diameter increases on increasing concentration of the inhibitor. The capacitive loop was related to charge transfer in the corrosion process, whereas the depressed form of the higher frequency loop reflects the surface nonhomogeneity of structural or interfacial origin, such as those found in adsorption processes [44]. Here contribution of all resistances correspond to the metal/solution interface, i.e., charge transfer resistance $\left(R_{\mathrm{ct}}\right)$, diffuse layer resistance $\left(R_{\mathrm{d}}\right)$, accumulation resistance $\left(R_{\mathrm{a}}\right)$, film resistance $\left(R_{\mathrm{f}}\right)$, etc. must be taken into account. So charge transfer resistance must be replaced by polarization resistance $\left(R_{\mathrm{p}}\right)$ [45] Nyquist plots can be represented by equivalent circuit (Fig. 8) where solution resistance $\left(R_{\mathrm{S}}\right)$ is shorted by constant phase element $(\mathrm{CPE})$ that is placed in parallel to polarization resistance $\left(R_{\mathrm{p}}\right)$.

The values of $R_{\mathrm{p}}$ were calculated from the difference in impedance at lower and higher frequencies [46]. The inhibition efficiency was calculated using polarization resistance according to the following equation:

$\operatorname{IE}(\%)=\frac{\left(R_{\mathrm{p}}\right)_{\mathrm{p}}-\left(R_{\mathrm{p}}\right)_{\mathrm{a}}}{\left(R_{\mathrm{p}}\right)_{\mathrm{p}}} \times 100$

Table 4 Impedance parameters for the corrosion of MS in $0.5 \mathrm{M} \mathrm{HCl}$ in absence and presence of different concentrations of inhibitors at $303 \mathrm{~K}$

\begin{tabular}{|c|c|c|c|c|c|c|c|}
\hline Inhibitor & Concentration (mM) & $R_{\mathrm{p}}\left(\Omega \mathrm{cm}^{2)}\right.$ & $Y_{\mathrm{o}}\left(\mu \Omega^{-1} \mathrm{~s}^{\mathrm{n}}\right)$ & $R_{\mathrm{s}}\left(\Omega \mathrm{cm}^{2}\right)$ & $n$ & $C_{\mathrm{dl}}\left(\mu \mathrm{F} \mathrm{cm}^{-2}\right)$ & IE $(\%)$ \\
\hline & Blank & 205 & 275.6 & 2.47 & 0.7631 & 112.9 & - \\
\hline \multirow[t]{4}{*}{ P1 } & 0.14 & 739 & 73.88 & 2.58 & 0.8641 & 46.76 & 72.3 \\
\hline & 0.21 & 919 & 55.66 & 4.54 & 0.8746 & 36.34 & 77.7 \\
\hline & 0.28 & 1106 & 20.15 & 1.21 & 0.9207 & 14.52 & 81.5 \\
\hline & 0.35 & 1519 & 45.46 & 2.14 & 0.8855 & 34.74 & 86.5 \\
\hline \multirow[t]{4}{*}{$\mathrm{P} 2$} & 0.14 & 939 & 55.9 & 1.303 & 0.8736 & 36.49 & 78.2 \\
\hline & 0.21 & 1161 & 38.26 & 4.064 & 0.8558 & 22.63 & 82.3 \\
\hline & 0.28 & 1372 & 19.32 & 1.194 & 0.9211 & 14.16 & 85.0 \\
\hline & 0.35 & 1572 & 20.29 & 1.271 & 0.9064 & 35.89 & 87.1 \\
\hline
\end{tabular}



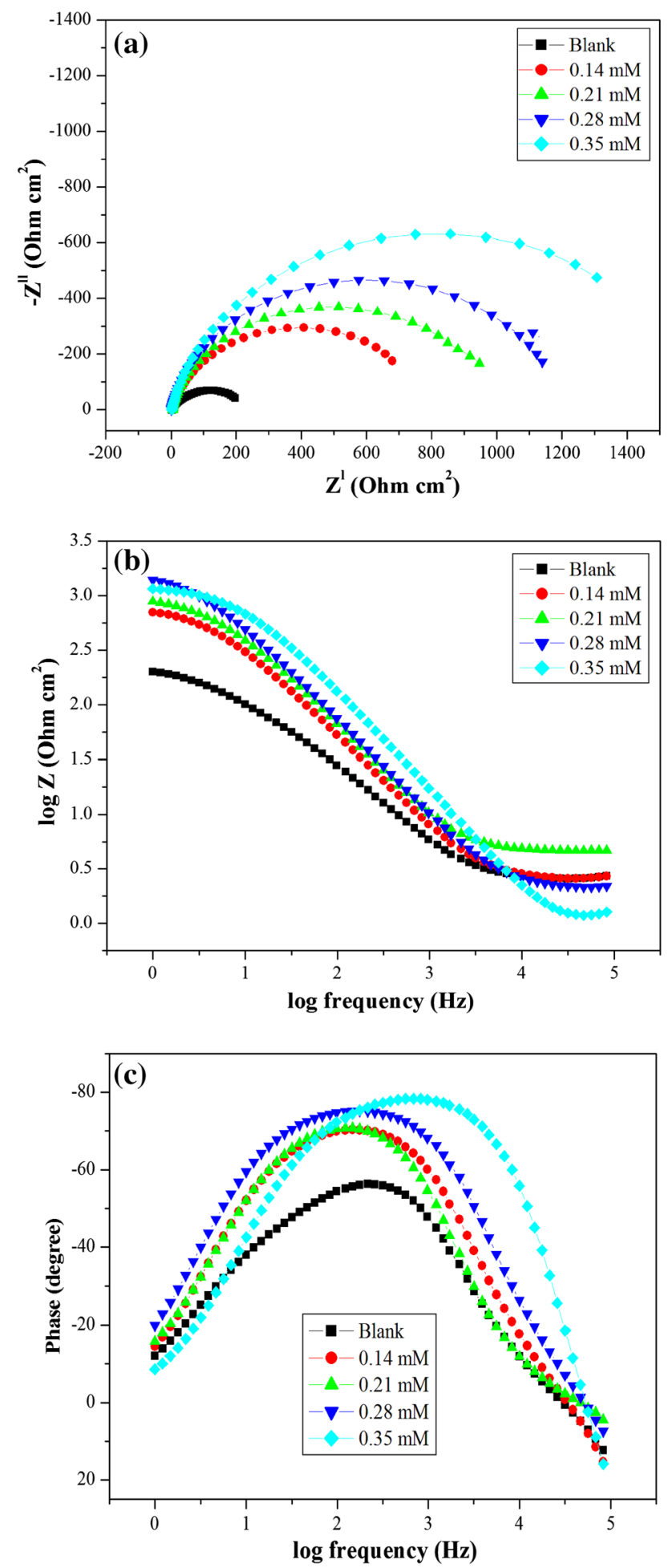

Fig. 6 a Nyquist plot. b Bode modulus plot. c Phase angle plot in the absence and presence of different concentrations of for P1

where $\left(R_{\mathrm{p}}\right)_{\mathrm{a}}$ and $\left(R_{\mathrm{p}}\right)_{\mathrm{p}}$ are the polarization resistances in the absence and presence of inhibitor, respectively. After the addition of inhibitors the polarization resistance $\left(R_{\mathrm{p}}\right)$
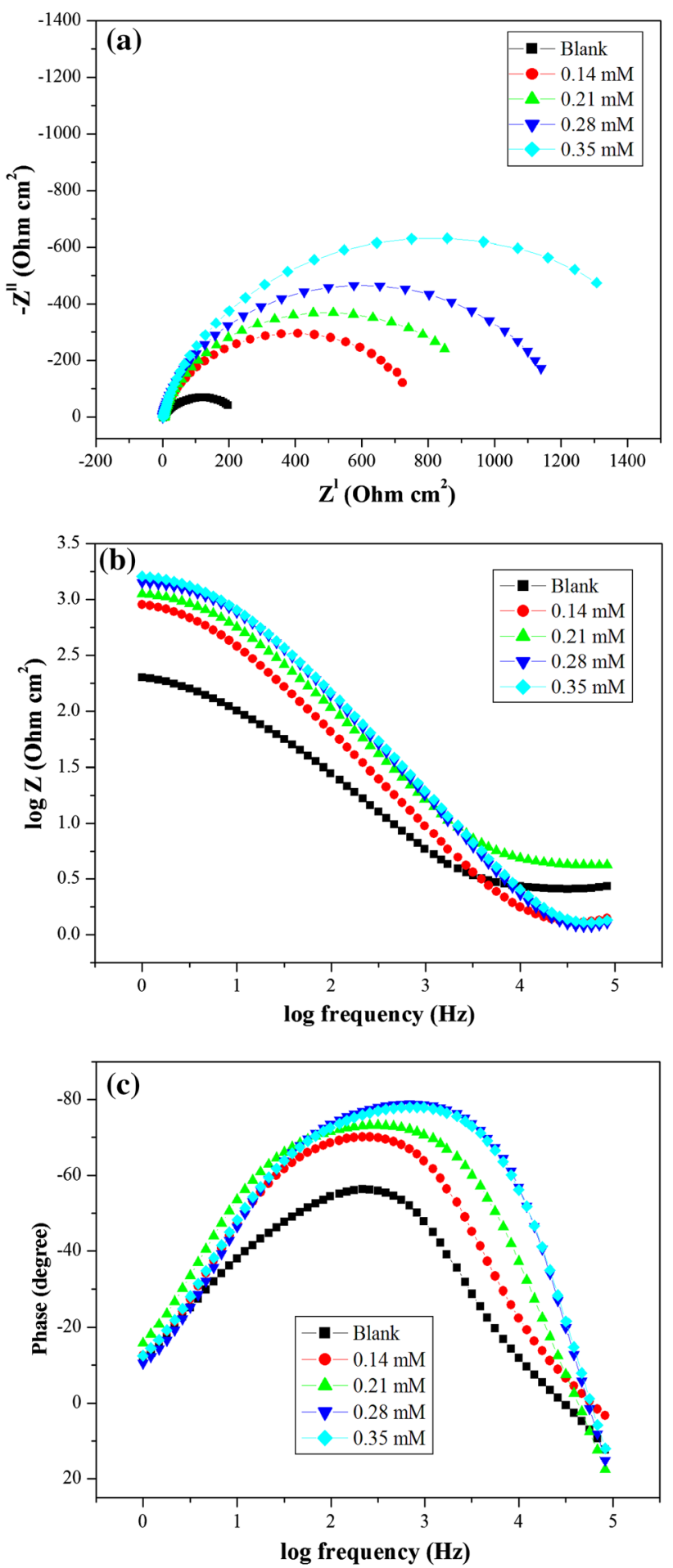

Fig. 7 a Nyquist plot. b Bode modulus plot. c Phase angle plot in the absence and presence of different concentrations of for P1

increases for both inhibitors. The increase in $R_{\mathrm{p}}$ value is due to the film formed on the steel surface which prevents the charge transfer. Such results were reported by many authors [47, 48]. Inhibition efficiency increases with the increase in the concentration of the inhibitors. As any other 


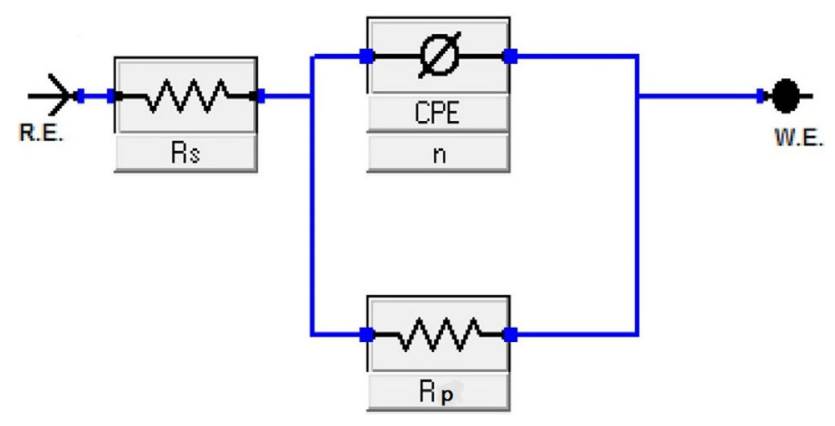

Fig. 8 Equivalent circuit model

electrochemical process corrosion also has two phases: (1) Oxidation of metal (charge transfer process). (2) The diffusion of metal ions from metal surface to the solution [49]. The film formed by the inhibitors P1 and P2 protects the metal by acting as a barrier to the diffusion of ions. Even though both P1 and P2 exhibit good inhibition efficiency, maximum efficiency is obtained for compound $\mathrm{P} 2$ because of the presence of plenty of electrons and an additional pyridine ring compared to $\mathrm{P} 1$.

CPE is a special element whose admittance is a function of angular frequency and whose phase is independent of frequency [50]. The impedance function of the CPE can be represented as follows:

$Z_{\mathrm{CPE}}=Y_{\mathrm{o}}^{-1}(i \omega)^{-1}$

where, $Y_{\mathrm{o}}$ is magnitude of CPE, $\omega$ is angular frequency (in $\left.\operatorname{rad~s}^{-1}\right), i^{2}=-1$ is the imaginary number, $n=\alpha /(\pi / 2)$ in which $\alpha$ is the phase angle of CPE. The value of $n$ signifies interphase parameter of working electrode. In this study $n$ value for blank is 0.76 , which increases by the addition of $\mathrm{P} 1$ (varying between 0.86 and 0.92 ) and P2 (0.87 and 0.92). Increase in the value of $\mathrm{n}$ by $\mathrm{P} 1$ and $\mathrm{P} 2$ addition represents capacitive behavior because for ideal capacitor $\mathrm{n}$ value is 1 . The double layer capacitance $\left(C_{\mathrm{dl}}\right)$ can be calculated from $\mathrm{CPE}$ parameters using the equation,

$C_{\mathrm{dl}}=\left(Y_{\mathrm{o}} R_{\mathrm{ct}}^{1-n}\right)^{1 / n}$

The decrease in $C_{\mathrm{dl}}$ is due to adsorption of inhibitors which displaces water molecules originally adsorbed on the MS surface which further decreases the active surface area [48]. Irregular trend in $C_{\mathrm{dl}}$ indicates the complexity of adsorption-desorption phenomenon. Such results were reported by many authors [51-53].

The single peak obtained in Bode plots for P1 and P2 indicates that the electrochemical impedance measurements fit well in one-time constant equivalent model. There is only one phase maximum in the Bode plot for both inhibitors, indicating only one relaxation process, which would be the charge transfer process, taking place at the metal-electrolyte interface [54]. The shift in phase angle is due to the protective film formed on the MS surface. The shift increases with increase in concentration of the inhibitors. Phase angle value for $\mathrm{P} 1$ and $\mathrm{P} 2$ varies between $60^{\circ}$ and $80^{\circ}$, whereas an ideal capacitor will be having by slope value of $90^{\circ}$.

\section{Potentiodynamic polarization}

Polarization measurements were performed to gain information regarding the kinetics of anodic and cathodic reactions. Tafel plots were drawn to study the mechanism of the inhibition process of P1 and P2 (Fig. 9). The electrochemical parameters, such as corrosion potential $\left(E_{\text {corr }}\right)$, corrosion current density $\left(i_{\text {corr }}\right)$, Tafel slopes $\left(b_{\mathrm{a}}, b_{\mathrm{c}}\right)$ and linear polarization resistance are listed in Table 5 .

Inhibition efficiency (IE \%) will be known by corrosion current density $\left(i_{\text {corr }}\right)$ calculated by the Tafel plot,
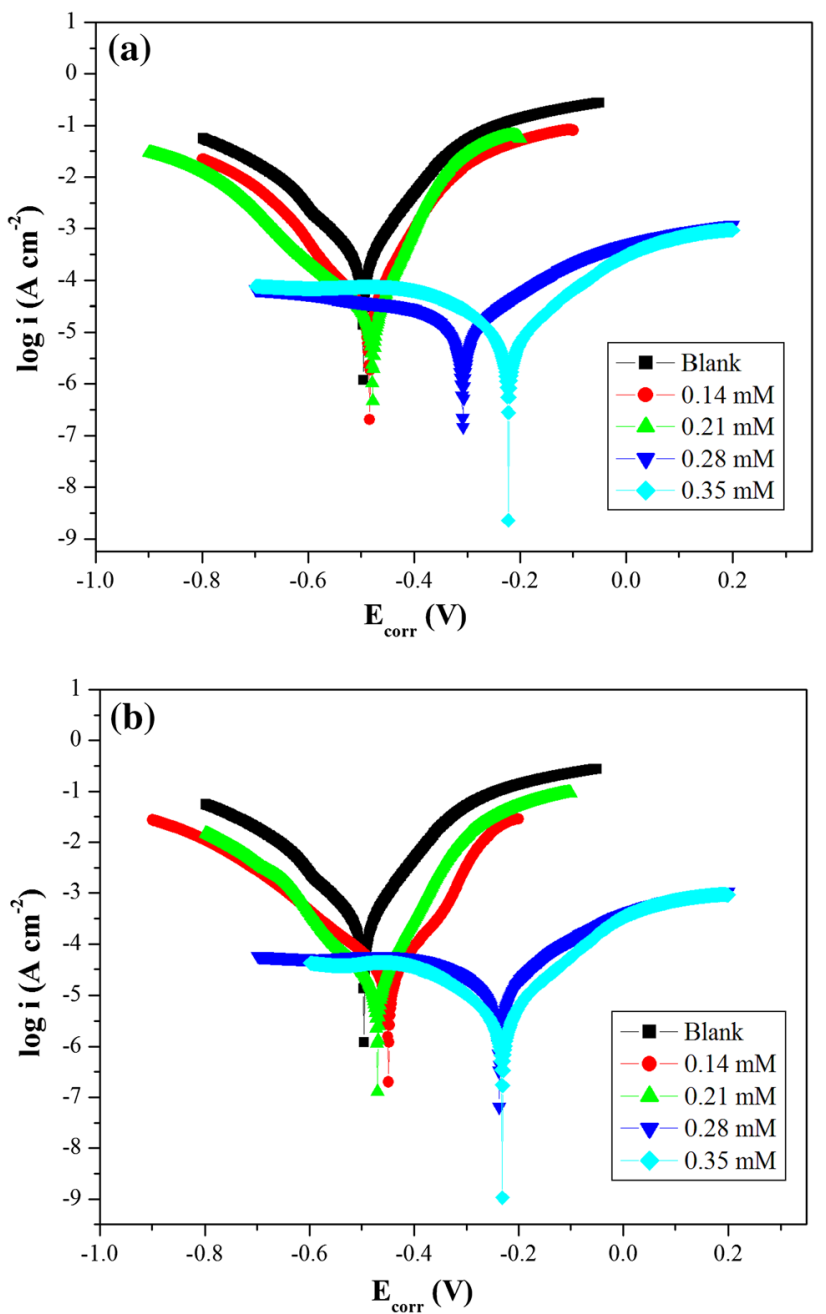

Fig. 9 Tafel plots for $\mathrm{MS}$ in $0.5 \mathrm{M} \mathrm{HCl}$ containing different concentration of $\mathbf{a}$ P1 and $\mathbf{b}$ P2 
Table 5 Potentiodynamic polarization parameters for the corrosion of MS in $0.5 \mathrm{M} \mathrm{HCl}$ in absence and presence of different concentrations of $\mathrm{P} 1$ and $\mathrm{P} 2$ at $303 \mathrm{~K}$

\begin{tabular}{|c|c|c|c|c|c|c|c|}
\hline Inhibitor & Concentration (mM) & $E_{\text {corr }}(\mathrm{mV})$ & $\begin{array}{l}i_{\text {corr }} \\
\left.(\mathrm{mA} \mathrm{cm})^{-2}\right)\end{array}$ & $b_{\mathrm{a}}\left(\mathrm{mV} \mathrm{dec}{ }^{-1}\right)$ & $b_{\mathrm{c}}\left(\mathrm{mV} \mathrm{dec}{ }^{-1}\right)$ & Linear polarization & IE $(\%)$ \\
\hline & Blank & -496 & 0.2728 & 76 & 100 & 69 & \\
\hline \multirow[t]{4}{*}{ P1 } & 0.14 & -484 & 0.0333 & 60 & 94 & 476 & 87.7 \\
\hline & 0.21 & -478 & 0.0232 & 47 & 120 & 636 & 91.5 \\
\hline & 0.28 & -308 & 0.0181 & 172 & 312 & 2668 & 93.4 \\
\hline & 0.35 & -222 & 0.0097 & 141 & 175 & 3525 & 96.4 \\
\hline \multirow[t]{4}{*}{ P2 } & 0.14 & -449 & 0.0283 & 73 & 129 & 713 & 89.6 \\
\hline & 0.21 & -470 & 0.0173 & 51 & 85 & 807 & 93.6 \\
\hline & 0.28 & -237 & 0.0137 & 128 & 214 & 2546 & 94.9 \\
\hline & 0.35 & -231 & 0.0052 & 120 & 172 & 5927 & 98.0 \\
\hline
\end{tabular}

$\mathrm{IE}(\%)=\frac{i_{\text {corr }}^{\mathrm{o}}-i_{\text {corr }}}{i_{\text {corr }}^{\mathrm{o}}} \times 100$

where $i_{\text {corr }}^{\mathrm{o}}$ and $i_{\text {corr }}$ are the uninhibited and the inhibited corrosion current densities, respectively.

Polarization is the shift in electrode potential from equilibrium value. By the addition of inhibitors there will be a shift in the corrosion potential value towards anodic region which is large in case of $\mathrm{P} 1$ and $\mathrm{P} 2$. This indicates that anodic reaction is predominantly hindered in the presence of inhibitors P1 and P2. Shift in anodic and cathodic Tafel slope values of P1 and P2 indicates that inhibitors are of mixed type promoting retardation of both anodic dissolution of $\mathrm{C}$-steel and cathodic hydrogen discharge reaction. The irregular trends of $b_{\mathrm{a}}$ and $b_{\mathrm{c}}$ values indicate the involvement of more than one type of species adsorbed on the metal surface [55]. The corrosion current values decrease with increasing concentration of $\mathrm{P} 1$ and $\mathrm{P} 2$ as a result of decrease in corrosion rate after the formation of adsorbed film. Linear polarization resistance increases with increase in concentration of inhibitors. According to Ferreira et al. the displacement in $E_{\text {corr }}$ is more than $85 \mathrm{mV}$ relating to the corrosion potential of the blank, the inhibitor is considered as a cathodic or anodic type. If the change in $E_{\text {corr }}$ is less than $85 \mathrm{mV}$, the corrosion inhibitor is regarded as a mixed type [56]. In the present case for both P1 and P2 shift is more than $85 \mathrm{mV}$ and it is anodic hence, the inhibitors are anodic.

\section{Quantum chemical calculations}

Quantum chemical calculations were done with complete geometry optimizations to explore the theoretical-experimental consistency of P1 and P2 using Ab initio method. This method reveals the binding ability of an organic compound thereby it is possible to predict the ability to retard the dissolution of metal in aggressive media. Inhibition efficiency is correlated to the molecular and structural parameters that can be obtained through theoretical calculations, such as chemical selectivity, reactivity and charge distribution [57]. In this way, various quantum chemical parameters, such as energies of highest occupied molecular orbital $\left(E_{\mathrm{HOMO}}\right)$, and the energies of lowest unoccupied molecular orbital ( $\left.E_{\mathrm{LUMO}}\right)$, the energy gap $(\Delta E)$, hardness $(\eta)$, softness $(\sigma)$, electron affinity $(A)$, electronegativity $(\chi)$ and ionization potential $(I)$ of P1 and P2 were calculated and compared with results obtained by gravimetric and electrochemical methods. The computed parameters of $\mathrm{P} 1$ and $\mathrm{P} 2$ are listed in Table 6.

All the quantum chemical structures are given in Table 7. According to Frontier Molecular Orbital (FMO) theory of chemical reactivity, transition of electron is due to interaction between highest occupied molecular orbital (HOMO) and lowest unoccupied molecular orbital (LUMO) of reacting species [58]. High $E_{\mathrm{HOMO}}$ facilitates adsorption by influencing the transport process through the adsorbed layer, whereas low lying $E_{\mathrm{LUMO}}$ induces a back donation of charge from the metal to the molecule [59]. In

Table 6 List of quantum chemical parameters for P1 and P2

\begin{tabular}{lll}
\hline Quantum chemical parameters & $\mathrm{P} 1$ & $\mathrm{P} 2$ \\
\hline Total energy $\left(\mathrm{kJ} \mathrm{mol}^{-1}\right)$ & $-3,278,010$ & $-3,927,246$ \\
Electronic kinetic energy $\left(\mathrm{kJ} \mathrm{mol}^{-1}\right)$ & $3,268,423$ & $3,917,446$ \\
Nuclear repulsion energy $\left(\mathrm{kJ} \mathrm{mol}^{-1}\right)$ & $6,357,794$ & $9,088,706$ \\
RMS gradient $\left(\mathrm{kJ} \mathrm{mol}^{-1} \mathrm{Ang}^{-1}\right)$ & 9.3766 & $5.02,388$ \\
Dipole $($ debyes $)$ & 8.0509 & 2.3956 \\
$E_{\mathrm{HOMO}}(\mathrm{eV})$ & -8.3873 & -7.2715 \\
$E_{\mathrm{LUMO}}(\mathrm{eV})$ & 2.3311 & 2.2679 \\
$\Delta E=E_{\mathrm{LUMO}}-E_{\mathrm{HOMO}}(\mathrm{eV})$ & 10.7185 & 9.5394 \\
Ionization potential, $I=-E_{\mathrm{HOMO}}$ & 8.3873 & 7.2715 \\
Electron affinity, $A=-E_{\mathrm{LUMO}}$ & -2.3311 & -2.2679 \\
Electronegativity $(\chi)$ & 3.0281 & 2.5018 \\
Hardness of the molecule $(\eta)$ & 5.3592 & 4.7697 \\
Softness $(\sigma)$ & 0.1865 & 0.2096 \\
\hline
\end{tabular}


Table 7 List of quantum chemical structures for P1 and P2

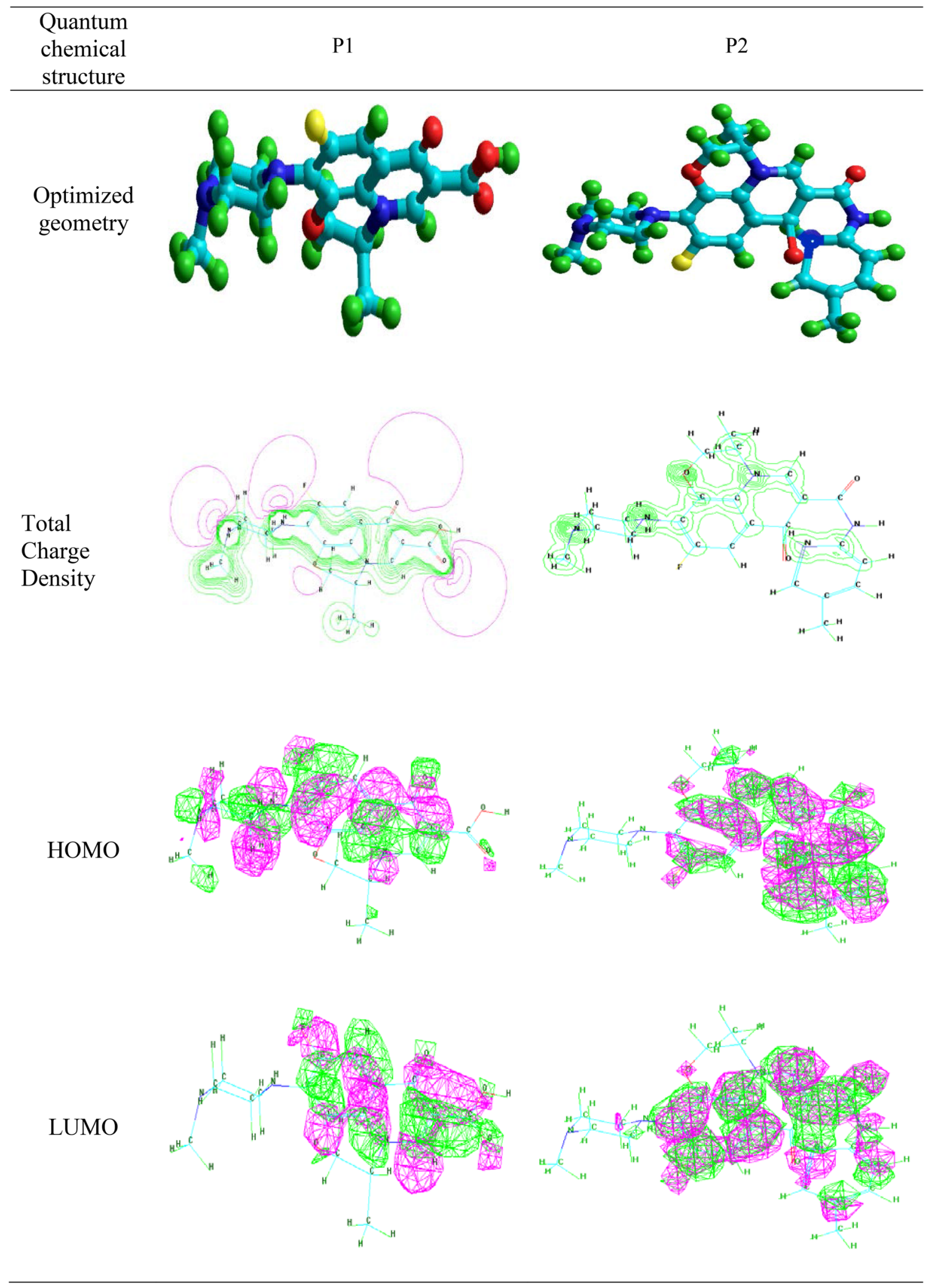


this study, $\mathrm{P} 2$ has higher $E_{\mathrm{HOMO}}$ value compared to P1, so it has better electron donating capacity. The better electron donation capacity of $\mathrm{P} 2$ can be correlated to the presence of nitrogen and oxygen atoms which contain lone pair of electrons and also aromatic electrons present on the ring. P2 has lower $E_{\text {LUMO }}$ value compared to P1, which reflects better acceptance of electrons which helps in back donation and hence, emerges as a better inhibitor. The electron density of HOMO is mostly distributed around the delocalised electrons in both $\mathrm{P} 1$ and $\mathrm{P} 2$ which shows involvement of these in adsorption. Lower value of $\Delta E$ ensures better efficiency because the energy required to remove an electron from the last occupied orbital will be low [60]. The trend for $\Delta E$ follows the order $\mathrm{P} 1>\mathrm{P} 2$ which suggests that $\mathrm{P} 2$ has higher interactions with the metal surface compared to P1. Molecular orbital (MO) theory can also be used to re-establish the results. As Fe atom is an electron pair acceptor it can be termed as Lewis acid whereas inhibitors $\mathrm{P} 1$ and $\mathrm{P} 2$ being electron donors act as base. According to MO concept, the overlap between LUMO of acid and HOMO of base acts as ruling factor for the formation of adsorption bond. The electron affinity of acid $(\mathrm{Fe})$ is $0.2 \mathrm{eV}$, the negative of which is the $E_{\mathrm{LUMO}}$ of acid. The $E_{\mathrm{HOMO}}$ of P1 and P2 are -8.387 and $-7.271 \mathrm{eV}$, respectively. Calculated values of energy gap between LUMO of acid and HOMO of two bases P1 and P2 works out to 8.187 and $7.071 \mathrm{eV}$, respectively. Lower the HOMO-LUMO energy gap, higher will be the HOMOLUMO overlap and stronger is the acid-base bond formation and higher the inhibition efficiency [49]. As the energy gap of $\mathrm{P} 2$ is less compared to $\mathrm{P} 1$, it can be deduced that the interaction between $\mathrm{P} 2$ and Fe surface can be easily established compared to $\mathrm{P} 1$, so $\mathrm{P} 2$ is more efficient in inhibiting MS corrosion. Ionization potential is a fundamental descriptor of chemical reactivity of atoms and molecules [61]. If the ionization potential is high then molecule is more stable and it is difficult to remove an electron to form adsorption bond. Among the two inhibitors, P1 has higher value for ionization potential as compared to $\mathrm{P} 2$. Hence, $\mathrm{P} 1$ is chemically more inert compared to $\mathrm{P} 2$, therefore, $\mathrm{P} 2$ has better inhibition efficiency. The dipole moment value is inconsistent on the use of dipole moment as a predictor of the direction of a corrosion inhibition reaction. In literature also, significant relation has not been mentioned between dipole moment and inhibition efficiency $[62,63]$. Electronegativity describes the tendency of an atom to attract electron density towards itself. According to Sanderson's electronegativity equalization principle [64], the molecule with high electronegativity quickly reaches equalization hence, low reactivity leads to lower inhibition efficiency. Among the studied molecules P1 has higher electronegativity hence, lower reactivity. Chemical hardness measures the resistance of an atom to a charge transfer whereas softness is the measure of the capacity of an atom or group of atoms to receive electrons [65]. According to HSAB theory of chemical reactivity, hard acids prefer to co-ordinate with hard bases and soft acids with soft bases. It is a well-known fact that Fe being a transition metal acts as soft acid. P2 had the least hardness and maximum softness so it stands out as the better inhibitor.

\section{Scanning electron microscopy}

Morphologies of MS in the absence and presence of optimum concentrations of $\mathrm{P} 1$ and $\mathrm{P} 2$ at $300 \mathrm{~K}$ are presented in Fig. 10a-d. The polished and smooth surface of MS before immersion in $\mathrm{HCl}$ is shown in Fig. 10a. After exposure of MS to uninhibited solution, the corroded surface appears to be damaged with cracks and pits and it is shown in Fig. 10b. When the surface is treated with inhibitor solutions the adsorbed film formed on the steel surface retards corrosion. In Fig. 10c, d surface of MS covered with inhibitors P1 and P2, respectively can be observed.

\section{Mechanism of inhibition}

Inhibition mechanism can be proposed on the basis of adsorption of P1 and P2 on steel surface. As the studied inhibitors are basic (containing nitrogen atoms) there is a chance of protonation. So in acidic solution, both neutral and cationic forms of inhibitors exist. It is assumed that $\mathrm{Cl}^{-}$ion first got adsorbed onto the positively charged metal surface by columbic attraction and then cationic form of inhibitor molecules can be adsorbed through electrostatic interactions between the positively charged molecules and the negatively charged metal surface [66]. The mechanism for the dissolution of $\mathrm{Fe}$ is reported by some authors [67].

$$
\begin{aligned}
& \mathrm{Fe}+\mathrm{Cl}^{-} \leftrightarrow\left(\mathrm{FeCl}^{-}\right)_{\mathrm{ads}} \\
& \left(\mathrm{FeCl}^{-}\right)_{\mathrm{ads}} \leftrightarrow(\mathrm{FeCl})_{\mathrm{ads}}+\mathrm{e}^{-} \\
& (\mathrm{FeCl})_{\mathrm{ads}} \leftrightarrow \mathrm{FeCl}^{+}+\mathrm{e}^{-} \\
& \mathrm{FeCl}^{+} \leftrightarrow \mathrm{Fe}^{+2}+\mathrm{Cl}^{-}
\end{aligned}
$$

Protonated form of P1 and P2 adsorbs on metal surface through $\left(\mathrm{FeCl}^{-}\right)$formed in step 13, forms $\left(\mathrm{FeCl}^{-} \mathrm{InhH}^{+}\right)$ and hence, steps 14,15 and 16 can be prevented. So anodic reactions will be retarded.

$$
\begin{aligned}
& \mathrm{Fe}+\mathrm{H}^{+} \leftrightarrow\left(\mathrm{FeH}^{+}\right)_{\mathrm{ads}} \\
& \left(\mathrm{FeH}^{+}\right)+\mathrm{e}^{-} \leftrightarrow(\mathrm{FeH})_{\mathrm{ads}} \\
& (\mathrm{FeH})_{\mathrm{ads}}+\mathrm{H}^{+}+\mathrm{e}^{-} \rightarrow \mathrm{Fe}+\mathrm{H}_{2}
\end{aligned}
$$



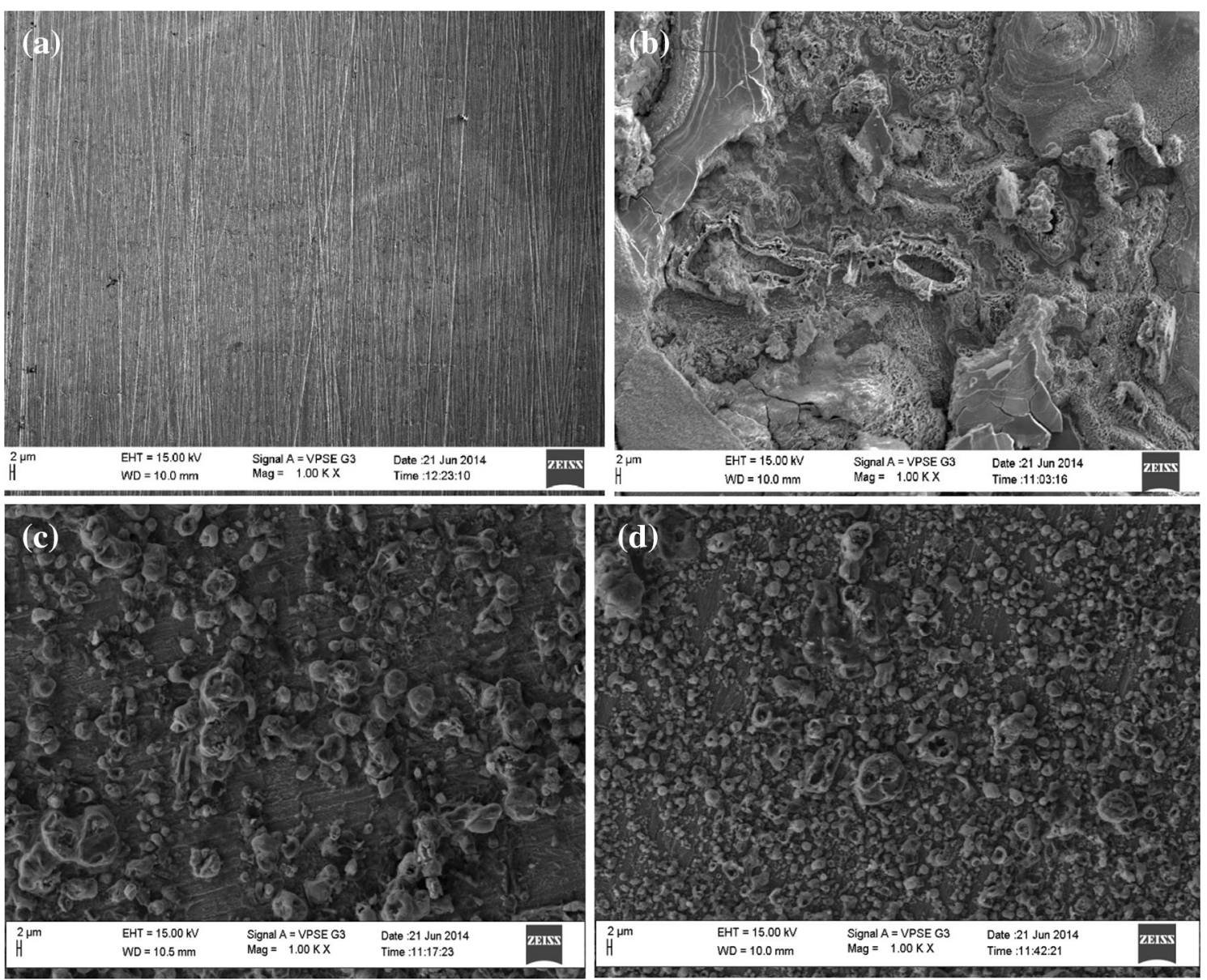

Fig. 10 SEM images of MS surface a polished, b immersed in $0.5 \mathrm{M} \mathrm{HCl}$, c immersed in $0.5 \mathrm{M} \mathrm{HCl}$ in the presence $0.35 \mathrm{mM}$ of $\mathrm{P}$, d immersed in $0.5 \mathrm{M} \mathrm{HCl}$ in the presence $0.35 \mathrm{mM}$ of $\mathrm{P} 2$

Protonated inhibitors also adsorbs at the cathodic sites in competition with hydrogen ions so hydrogen evolution will be reduced.

Along with electrostatic force of attraction, inhibitors also adsorb on the MS surface through chemical adsorption. Both $\mathrm{P} 1$ and $\mathrm{P} 2$ contain hetero atoms ( $\mathrm{N}$ and $\mathrm{O}$ ), extended $\pi$ electron system which helps in making effective co-ordinate bond with MS surface. Electron releasing methyl groups are also present which increases electron density on the ring. P2 contains an extended pyridine ring which also gives good contribution in decreasing corrosion rate. So inhibition takes place through both physisorption and chemisorption.

\section{Conclusion}

The following conclusions can be derived from the studies.

1. Levofloxacin derived amide (P2) and Levofloxacin (P1) showed very good activity in preventing corrosion of MS in hydrochloric acid media. P2 shows higher inhibition efficiency compared to P1.

2. Inhibition efficiency of MS varies directly with the concentration and inversely with the temperature.

3. Adsorption of both inhibitions follows Langmuir isotherm.

4. EIS measurements show that polarization resistance increases and double layer capacitance decreases on adding inhibitors.

5. Potentiondynamic polarization experiments reveal that $\mathrm{P} 1$ and $\mathrm{P} 2$ are anodic inhibitors.

6. Surface studies show the formation of adsorbed inhibitor layer on the metal surface.

7. From quantum chemical methods it is revealed that $\mathrm{P} 2$ has better electron donating ability compared to P1. This supports experimental results very well.

Acknowledgments One of the authors (T. K. C) received NON-NET fellowship from University grants Commission, New Delhi (ORDER NO. DV9/403/Misc/2014-15 dated 13/02/2015) and it is gratefully acknowledged. 
Open Access This article is distributed under the terms of the Creative Commons Attribution 4.0 International License (http://crea tivecommons.org/licenses/by/4.0/), which permits unrestricted use, distribution, and reproduction in any medium, provided you give appropriate credit to the original author(s) and the source, provide a link to the Creative Commons license, and indicate if changes were made.

\section{References}

1. Singh AK, Ebenso EE (2013) Cefotatan; a new corrosion inhibitor for corrosion of mild steel in hydrochloric acid solution. Int J Electrochem Sci 8:10903-10909

2. Zaafarany IA (2013) Corrosion inhibition of mild steel in hydrochloric acid solution using cationic surfactant olyel-amido derivatives. Int J Electrochem Sci 8:9531-9542

3. Loto RT, Loto CA, Popoola API (2012) Corrosion inhibition of thiourea and thiadiazole derivatives: a review. J Mater Environ Sci 3:885-894

4. Kumar RS, Danaee I, Avei RM, Vijayan M (2015) Quantum chemical and experimental investigations on equipotent effects of (+) $\mathrm{R}$ and (-) $\mathrm{S}$ enantiomers of racemic amisulpride as ecofriendly corrosion inhibitors for mild steel in acidic solution. J Mol Liq 212:168-186

5. Verma CB, Ebenso EE, Bahadur I, Obot IB, Quraishi MA (2015) 5-(phenylthio)-3H-pyrrole-4-carbonitriles as effective corrosion inhibitors for mild steel in $1 \mathrm{M} \mathrm{HCl}$ : Experimental and theoretical investigation. J Mol Liq 212:209-218

6. Gu T, Chen Z, Jiang X, Limei Z, Liao Y, Duan M, Wang H, Pu Q (2015) Synthesis and inhibition of $\mathrm{N}$-alkyl-2-(4-hydroxybut-2ynyl) pyridinium bromide for mild steel in acid solution: BoxBehnken design optimization and mechanism probe. Corros Sci 90:118-132

7. Eddy NO, Odoemelam SA, Ekwumemgbo P (2009) Inhibition of the corrosion of mild steel in $\mathrm{H}_{2} \mathrm{SO}_{4}$ by penicillin G. Sci Res Essays 4:33-38

8. Eddy NO, Ebenso EE, Ibok UJ (2010) Adsorption, synergistic inhibitive effect and quantum chemical studies of ampicillin (AMP) and halides for the corrosion of mild steel in $\mathrm{H}_{2} \mathrm{SO}_{4}$. J Appl Electrochem 40:445-456

9. Abdallah M (2004) Antibacterial drugs as corrosion inhibitors for corrosion of aluminium in hydrochloric acid solution. Corros Sci 46:1981-1996

10. Pang XH, Guo WJ, Li WH, Xie JD, Hou BR (2008) Electrochemical, quantum chemical and SEM investigation of the inhibiting effect and mechanism of ciprofloxacin, norfloxacin and ofloxacin on the corrosion for mild steel in hydrochloric acid. Sci China Ser B Chem 51:928-936

11. Pang X, Ran X, Kuang F, Xie J, Hou B (2010) Inhibiting effect of ciprofloxacin, norfloxacin and ofloxacin on corrosion of mild steel in hydrochloric acid. Chin J Chem Eng 18:337-345

12. Ebenso EE, Obot IB, Murulana LC (2010) Quinoline and its derivatives as effective corrosion inhibitors for mild steel in acidic medium. Int J Electrochem Sci 5:1574-1586

13. Shukla SK, Quraishi MA (2010) The effects of pharmaceutically active compound doxycycline on the corrosion of mild steel in hydrochloric acid solution. Corros Sci 52:314-321

14. El-Naggar MM (2007) Corrosion inhibition of mild steel in acidic medium by some sulfa drugs compounds. Corros Sci 49:2226-2236

15. Singh A, Singh AK, Quraishi MA (2010) Dapsone: a novel corrosion inhibitor for mild steel in acid media. Open Corros $\mathbf{J}$ $2: 43-51$
16. Obot IB (2009) Synergistic effect of nizoral and iodide ions on the corrosion inhibition of mild steel in sulphuric acid solution. Port Electrochim Acta 27:539-553

17. Solmaz R, Kardas G, Yazici B, Erbil M (2005) Inhibition effect of rhodanine for corrosion of mild steel in hydrochloric acid solution. Prot Met 41:628-632

18. Noel GJ (2009) A review of levofloxacin for the treatment of bacterial infections. Clin Med Ther 1:433-458

19. Gece G (2011) Drugs: a review of promising novel corrosion inhibitors. Corros Sci 53:3873-3898

20. Eddy NO, Stanislav R, Stoyanovand Ebenso EE (2010) Fluoroquinolones as corrosion inhibitors for mild steel in acidic medium; experimental and theoretical studies. Int J Electrochem Sci 5:1127-1150

21. Pang X, Zhang Y, Jie Z, Xie J, Baorong H (2011) Corrosion inhibition and mechanisms study on pipemidic acid, levofloxacin and ciprofloxacin for mild steel in $0.5 \mathrm{~mol} / \mathrm{L} \mathrm{H}_{2} \mathrm{SO}_{4}$. Acta Chim Sin 69:483-491

22. Gurudatt DM, Mohana KN (2014) Synthesis of new pyridine based 1, 3, 4-oxadiazole derivatives and their corrosion inhibition performance on mild steel in $0.5 \mathrm{M}$ hydrochloric acid. Ind Eng Chem Res 53:2092-2105

23. Chaitra TK, Mohana KN, Tandon HC (2015) Thermodynamic, electrochemical and quantum chemical evaluation of some triazole Schiff bases as mild steel corrosion inhibitors in acid media. J Mol Liq 211:1026-1038

24. Mohana KN, Badiea AM (2008) Effect of sodium nitrite-borax blend on the corrosion rate of low carbon steel in industrial water medium. Corros Sci 50:2939-2947

25. Chaitra TK, Mohana KN, Tandon HC (2016) Study of new thiazole based pyridine derivatives as potential corrosion inhibitors for mild steel: theoretical and experimental approach. Int J Corros 2016:21. doi:10.1155/2016/9532809

26. Harish KP, Mohana KN, Mallesha L, Veeresh B (2014) Synthesis and in vivo anticonvulsant activity of 2-methyl-2-[3-(5-piperazin1-yl-[1,3,4]oxadiazol-2-yl)-phenyl]-propionitrile derivatives. Arch Pharm Chem Life Sci 346:1-12

27. Bentiss F, Lebrini M, Legrenee M (2005) Thermodynamic characterization of metal dissolution and inhibitor adsorption processes in mild steel/2,5-bis(n-thienyl)-1,3,4-thiadiazoles/hydrochloric acid system. Corros Sci 47:2915-2931

28. Obi-Egbedi NO, Obot IB (2013) Xanthione: a new and effective corrosion inhibitor for mild steel in sulphuric acid solution. Arab J Chem 6:211-223

29. Herrag L, Hammouti B, Elkadri S, Aountini A, Jama C, Vezin H, Bentiss F (2010) Adsorption properties and inhibition of mild steel corrosion in hydrochloric solution by some newly synthesized diamine derivatives: experimental and theoretical investigations. Corros Sci 52:3042-3051

30. Singh AK, Quraishi MA (2011) Investigation of the effect of disulfiram on corrosion of mild steel in hydrochloric acid solution. Corros Sci 53:1288-1297

31. Fouda AS, Al-Sarawy AA, El-Katori EE (2006) Pyrazolone derivatives as corrosion inhibitors for C-steel in hydrochloric acid solution. Desalination 201:1-13

32. Guan NM, Xueming L, Fei L (2004) Synergistic inhibition between o-phenanthroline and chloride ion on cold rolled steel corrosion in phosphoric acid. Mater Chem Phys 86:59-68

33. Yadav DK, Quraishi MA, Maiti B (2012) Inhibition effect of some benzylidenes on mild steel in $1 \mathrm{M} \mathrm{HCl}$ : an experimental and theoretical correlation. Corros Sci 55(2012):254-266

34. Ghazoui A, Saddik R, Benchat N, Hammouti B, Guenbour M, Zarrouk A, Ramdani M (2012) The role of 3-amino-2phenylimidazo[1,2-a]pyridine as corrosion inhibitor for C38 steel in $1 \mathrm{M} \mathrm{HCl}$. Der Pharma Chem 4:352-364 
35. Obi-Egbedi NO, Obot IB (2011) Inhibitive properties, thermodynamic and quantum chemical studies of alloxazine on mild steel corrosion in $\mathrm{H}_{2} \mathrm{SO}_{4}$. Corros Sci 53:263-275

36. Behpour M, Ghoreishi SM, Soltani N, Salavati-Niasari M, Hamadanian M, Gandomi A (2008) Electrochemical and theoretical investigation on the corrosion inhibition of mild steel by thiosalicylaldehyde derivatives in hydrochloric acid solution. Corros Sci 50:2172-2218

37. Solmaz R, Altunbas E, Kardas G (2011) Adsorption and corrosion inhibition effect of 2-((5 mercapto-1, 3, 4-thiadiazol-2 ylimino) methyl) phenol Schiff base on mild steel. Mat Chem Phys 125:796-801

38. Singh A, Ebenso EE, Quraishi MA (2012) Theoretical and electrochemical studies of metformin as corrosion inhibitor for mild steel in hydrochloric acid solution. Int J Electrochem Sci 7:4766-4779

39. Solmaz R (2014) Investigation of corrosion inhibition mechanism and stability of vitamin $\mathrm{B} 1$ on mild steel in $0.5 \mathrm{M} \mathrm{HCl}$ solution. Corros Sci 81:75-84

40. Solmaz R (2010) Investigation of the inhibition effect of 5-((E)-4phenylbuta-1,3-dienylideneamino)-1,3,4-thiadiazole-2-thiol Schiff base on mild steel corrosion in hydrochloric acid. Corros Sci 52:3321-3330

41. Heakal FE, Fouda AS, Radwan MS (2011) Inhibitive effect of some thiadiazole derivatives on C-steel corrosion in neutral sodium chloride solution. Mat Chem Phys 125:26-36

42. Ayati NS, Khandandela S, Momeni M, Moayed MH, Davoodi A, Rahimizadeh M (2011) Inhibitive effect of synthesized 2-(3pyridyl)-3, 4-dihydro-4-quinazolinone as a corrosion inhibitor for mild steel in hydrochloric acid. Mat Chem Phys 126:873-879

43. Benabdellah M, Tounsi A, Khaled KF, Hammouti B (2011) Thermodynamic, chemical and electrochemical investigations of 2-mercapto benzimidazole as corrosion inhibitor for mild steel in hydrochloric acid solutions. Arab J Chem 4:17-24

44. Tao Z, Zhang S, Li W, Hou B (2010) Adsorption and corrosion inhibition behavior of mild steel by one derivative of benzoictriazole in acidic solution. Ind Eng Chem Res 49:2593-2599

45. Solmaz R, Kardas G, Culha M, Yazici B, Erbil M (2008) Investigation of adsorption and inhibitive effect of 2-mercaptothiazoline on corrosion of mild steel in hydrochloric acid media. Electrochim Acta 53:5941-5952

46. Tsuru T, Haruyama S, Gijutsu B (1978) Corrosion inhibition of iron by amphoteric surfactants in $2 \mathrm{M} \mathrm{HCl}$. J Jpn Soc Corros Eng 27:573-581

47. Ozcan M, Dehri I, Erbil M (2004) Organic sulphur-containing compounds as corrosion inhibitors for mild steel in acidic media: correlation between inhibition efficiency and chemical structure. Appl Surf Sci 236:155-164

48. Khaled KF (2008) New synthesized guanidine derivative as a green corrosion inhibitor for mild steel in acidic solutions. Int $\mathbf{J}$ Electrochem Sci 3:462-475

49. Ahamed I, Prasad R, Quraishi MA (2010) Experimental and theoretical investigations of adsorption of fexofenadine at mild steel/hydrochloric acid interface as corrosion inhibitor. J Solid State Electrohem 14:2095-2105

50. Singh AK (2012) Inhibition of mild steel corrosion in hydrochloric acid solution by 3-(4-((z)-indolin-3-ylideneamino) phenylimino) indolin-2-one. Ind Eng Chem Res 51:3215-3223
51. Karthik R, Muthukrishnan P, Chen S, Jeyaprabha B, Prakash P (2015) Anti-corrosion inhibition of mild steel in $1 \mathrm{M}$ hydrochloric acid solution by using tiliacoraaccuminata leaves extract. Int J Electrochem Sci 10:3707-3725

52. Ergun U, Yuzer D, Emregu KC (2008) The inhibitory effect of bis-2,6-(3,5-dimethylpyrazolyl) pyridine on the corrosion behaviour of mild steel in $\mathrm{HCl}$ solution. Mat Chem Phys 109:492-499

53. Quraishi MA, Sudheer Ansari KR, Ebenso EE (2012) 3-Aryl substituted triazole derivatives as new and effective corrosion inhibitors for mild steel in hydrochloric acid solution. Int J Electrochem Sci 7:7476-7492

54. Yadav M, Kumar S (2014) Experimental, thermodynamic and quantum chemical studies on adsorption and corrosion inhibition performance of synthesized pyridine derivatives on N80 steel in $\mathrm{HCl}$ solution. Surf Interface Anal 46:254-268

55. Fouda AS, Elewady YA, El-Aziz HKA (2012) Corrosion inhibition of carbon steel by cationic surfactants in $0.5 \mathrm{M} \mathrm{HCl}$ solution. J Chem Sci Technol 1:45-53

56. Ferreira ES, Giancomlli C, Giacomlli FC, Spinelli A (2004) Evaluation of the inhibitor effect of L-ascorbic acid on the corrosion of mild steel. Mater Chem Phys 83:129-134

57. Oguike RS, Kolo AM, Shibdawa AM, Gyenna HA (2013) Density functional theory of mild steel corrosion in acidic media using dyes as inhibitor: adsorption onto $\mathrm{Fe}(110)$ from gas phase. ISRN Phys Chem Article no. 175910. doi:10.1155/2013/175910

58. Musa AY, Kadhum AH, Mohamad AB, Rohoma AB, Mesmari H (2010) Electrochemical and quantum chemical calculations on 4, 4-dimethyloxazolidine-2-thione as inhibitor for mild steel corrosion in hydrochloric acid. J Mol Struc 969:233-237

59. Oguzie Onuoha GN, Onuchukwu AI (2005) Inhibitory mechanism of mild steel corrosion in $2 \mathrm{M}$ sulphuric acid solution by methylene blue dye. Mat Chem Phys 89:305-311

60. Zarrok H, Zarrouk A, Salghi R, Oudda H, Hammouti B, Assouag M, Taleb M, Touhami ME, Bouachrine M, Boukhris S (2012) Gravimetric and quantum chemical studies of 1-[4-acetyl-2-(4chlorophenyl)quinoxalin-1(4H)-yl]acetone as corrosion inhibitor for carbon steel in hydrochloric acid solution. J Chem Pharmac Res 4:5056-5066

61. Udayakala P, Rajendran TV, Gunashekaran S (2015) Theoretical approach to the corrosion inhibition efficiency of some pyrimidine derivatives using DFT method. J Comput Methods in Mol Design 2:1-12

62. Gao G, Liang C (2007) Electrochemical and DFT studies of $\beta$ amino-alcohols as corrosion inhibitors for brass. Electrochim Acta 52:4554-4559

63. Khalil N (2003) Quantum chemical approach of corrosion inhibition. Electrochim Acta 48:2635-2640

64. Geerlings P, Proft FD (2002) Chemical reactivity as described by quantum chemical methods. Int J Mol Sci 3:276-309

65. Senet P (1997) Chemical hardnesses of atoms and molecules from frontier orbitals. Chem Phys Lett 275:527-532

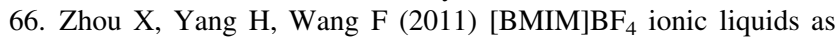
effective inhibitor for carbon steel in alkaline chloride solution. Electrochim Acta 56:4268-4275

67. Yousefi A, Javadian S, Dalir N, Kakemam J, Akbari J (2015) Imidazolium-based ionic liquids as modulators of corrosion inhibition of SDS on mild steel in hydrochloric acid solutions: experimental and theoretical studies. RSC Adv 5:11697-11713 